\title{
Pharmaceuticals and personal care product residues in the environment: identification and remediation
}

\author{
E. Heath ${ }^{1}$, T. Kosjek ${ }^{1}$, P. Cuderman ${ }^{1} \&$ B. Kompare ${ }^{2}$ \\ ${ }^{1}$ Jožef Stefan Institute, Department of Environmental Sciences, Slovenia \\ ${ }^{2}$ University of Ljubljana, Faculty of Civil and Geodetic Engineering, \\ Institute of Sanitary Engineering, Slovenia
}

\begin{abstract}
In this paper we investigate the possible impact on the ecosystems of the active ingredients in pharmaceutical and personal care products (PPCPs). These molecules are in their nature biologically active substances whose effects, once released into the environment, remain unclear. Commonly used drugs and cosmetics have been detected in drinking and surface waters suggesting possible consequences for environment and human health. Considering the possible bioaccumulation in the food chain and chronic toxicity due to a combination effect it is necessary to better understand their environmental fate.

Pharmacologically and cosmetic active substances involved in our study were chosen according to their wide application in central Europe and to their suspected toxicity and bioaccumulation (nonsteroidal anti-inflammatory drugs NSAIDs, sunscreen agents, antiseptics). For isolation and identification of the selected compounds GC-MS procedure has been developed in our laboratory. To determine the presence of PPCP in the Slovene aquatic environment, different water samples (river, potable, well, lake, sea, swimming pool and waste water) were analyzed. The results show that the average PPCP contamination in Slovenian waters is comparable to published results for Central and Western Europe. To understand the environmental fate of these substances we studied the biodegradation paths in controlled conditions using laboratory scale bioreactor facilities. Degradation experiments were made with spiked water samples of different concentrations of pollutants $(1 \mu \mathrm{g} / \mathrm{L}-1 \mathrm{ng} / \mathrm{L})$ starting with activated biomass from the active wastewater treatment plant. After 6 months of continuous operation, a steady removal of all observed compounds (NSAID representatives) was achieved (up to $90 \%$ ). In the future other PPCP representatives will be studied and the reactor configuration will be optimized. Keywords: pharmaceutical, personal care products, NSAIDs, UV filters, antimicrobial, analytical procedure, environmental samples.
\end{abstract}




\section{Introduction}

The focus of environmental research is extending beyond classic environmental pollutants, such as PCBs, dioxins, and pesticides, to a group of compounds with a common name "new emerging contaminants" such as pharmaceuticals and personal care products (PPCPs). Thousands of tons of pharmacologically active substances are used annually to treat or prevent illnesses, or to help people to face up to the stresses of modern life. As well as pharmaceuticals, the amount of chemicals used in personal care products is in the thousands of tons per years. The world's population consumes enormous quantities of skin care products, dental care products, sunscreen agents, to name just a few (Ternes et al. [1]) In the future, their application is predicted to increase due to the growth in the world's population, longer life expectancy, development of pharmaceutical industry and an increased awareness of the danger that modern life poses over our civilization, between which we will mention only thinning of ozone layer, DNA radical damage and unphysiological aging.

The main sources of pharmaceutical residues in the environment are human and veterinary medicine and as part of the waste produced by the pharmaceutical industry. Unlike pharmaceuticals, personal care products may enter surface waters directly, for example, from the skin during swimming and bathing or indirectly via wastewaters. The discharge of therapeutic and cosmetic agents from production facilities, hospitals and private household effluents as well as improper disposal of unused or expired products, direct discharge of sunscreens and veterinary medicines lead to surface water, ground water and drinking water where they pose a potential risk to humans. During and after treatment, humans and animals excrete a combination of intact and metabolized pharmaceuticals. Consequently, many bioactive compounds enter wastewaters and the receiving water bodies without any tests for specific environmental effects and therefore it is both the parent compound and active metabolites that should be the subject for a risk assessment.

The acute toxic effects of pharmaceutical compounds are well investigated, since they are required for a marketing authorization permit. On the other hand the toxicity of cosmetic compounds does not need to be assessed by detailed clinical trials even though some cosmetics are known to cause local irritations on sensitive skin and there is no reliable data regarding their toxicity after ingestion. The effects of continuous low dosage ingestion are not adequately recognized in both, pharmaceutical and cosmetic compounds, moreover, synergistic or additive toxic effects are possible between different parent compounds and/or metabolites. Also, it is not known how different the toxicity of complex mixtures are from that of individual compounds and although the amounts of pharmaceutical and personal care product (PPCP) residues, when released to the environment, are low, their continuous input may lead to chronic low level exposures and accumulation with potential negative effects on the environment. Considering the possible bioaccumulation in the food web and chronic toxicity due to a synergistic or additive effect, it is necessary therefore to understand better their environmental fate. 
To date commonly used pharmaceuticals have been detected in waste, surface and even drinking waters (Kosjek et al. [2], Kümmerer [3]), cosmetic residues in surface waters (Giokas et al. [4]) and antimicrobial agents in waste and surface waters (Lindström et al. [5]). PPCPs are often subjected to waste water treatment and therefore, it is essential to know what is the WWTP efficiency to eliminate them from wastewaters to be aware of the amounts of these compounds that can enter environmental cycle this way.

This study reports on the development of analytical procedures for determination of selected pharmaceutical and personal care product active ingredients in environmental and wastewater samples and determination of selected PPCPs in aqueous samples from Slovenia. Further, elimination of the pharmaceutical compounds was studied in a small-scale pilot wastewater treatment plant (PWWTP).

\section{Experimental}

\subsection{Chemicals}

Pharmacologically and PCP active substances involved in our study were chosen according to their wide application in Slovenia and Central Europe and to their suspected toxicity or bioaccumulation. The pharmaceutical substances belong to a group of NonSteroidal AntiInflammatory Drugs (NSAIDs): Ibuprofen, Ketoprofen, Diclofenac and Naproxen. UV filters with commercial name Eusolex (Homosalate, 4-Methylbenzylidene Camphor, Benzophenone-3, Octocrylene, Butyl Methoxydibenzoylmethane, Ethylhexyl Methoxycinnamate) and anti-microbial agents (Clorophene and Triclosan) were chosen for our study.

\subsection{Analytical method}

In order to determine the presence of PPCP residues in various water samples (waste, surface, ground, tap and drinking water), we developed an analytical procedure which involves solid phase extraction (SPE) and gas chromatography with mass spectrometric detection (GC-MSD) [2]. Prior to extraction, water samples were filtered ( $0.45 \mu \mathrm{m}$ filter, Sartorius, Goettingen, Germany) and acidified to $\mathrm{pH} 2$ to ensure successful trapping of the acidic compounds onto the SPE sorbent. For SPE commercially available $3 \mathrm{~mL}$ SPE cartridges with $60 \mathrm{mg}$ of Strata $^{\mathrm{TM}} \mathrm{X}$ (surface modified styrene-divinylbenzene polymer) sorbent (Phenomenex ${ }^{\circledR}$, Torrance, ZDA) were applied. For each group of compounds (pharmaceuticals and UV filters with antimicrobial agents), different SPE extraction and elution procedures were applied. For determination of NSAIDs the cartridges were first conditioned with methanol, which was removed with acidified deionised water having the same $\mathrm{pH}$ as the sample $(2,6)$. Compounds of interest were retained on the sorbent and afterwards eluted with 1,5 mL of methanol. The methanol from the extract was evaporated under a stream of $\mathrm{N}_{2}$ and replaced with toluene. For the determination of UV filters and antimicrobial agents, the cartridges were first conditioned with $1,5 \mathrm{~mL}$ ethyl acetate/ dichloromethane $(1: 1, \mathrm{v} / \mathrm{v})$, followed by $1,5 \mathrm{~mL}$ of methanol, which was then removed with acidified deionised water having the same $\mathrm{pH}$ as sample loaded 
afterwards $(\mathrm{pH}=2,6)$. Selected compounds were eluted from SPE sorbent with $1,5 \mathrm{~mL}$ of ethyl acetate/ dichloromethane $(1: 1, \mathrm{v} / \mathrm{v})$. The extract solvent was evaporated and replaced by toluene. The compounds were derivatizated to their trimethylsilyl esters using N-methyl-N-trimethylsilyl trifluoracetamide (MSTFA) to convert the polar compounds to volatile esters. GC-MSD analysis was performed on a HP 6890 gas chromatograph (Hewlett-Packard, Waldbronn, Germany), fitted with a HP-5MS capillary column and mass spectrometric detection.

\subsection{Elimination of pharmaceuticals on pilot wastewater treatment plant (PWWTP)}

To study the elimination of compounds of interest in WWTP, we designed a PWWTP that mimics the classical treatment in a municipal WWTP. The PWWTP uses active sludge obtained from Slovenian municipal wastewater treatment plant. The design of the PWWTP consists of three parallel reactors. Two reactors $\mathrm{R} 1$ and $\mathrm{R} 2$ operate under continuous input of higher $\left(\mathrm{R} 1=0,05 \mathrm{mg} \mathrm{L}^{-1}\right)$ and lower $\left(\mathrm{R} 2=0,005 \mathrm{mg} \mathrm{L}^{-1}\right)$ concentrations of selected NSAIDs, while R0 is a control reactor. We designed the reactors to be economical in terms of the operating costs while containing a sufficient volume to allow installation of equipment (aerators, pumps) and maintenance (cleaning, repair). The reactor design was optimized at 4,0 $\mathrm{L}$ and configured to allow the reactor to be operated under aerobic and anaerobic, or anoxic conditions. Figures 1 and 2 show the layout of the reactor. Each reactor consists of a selector, anaerobic, and aerobic chamber and a sedimentation basin.

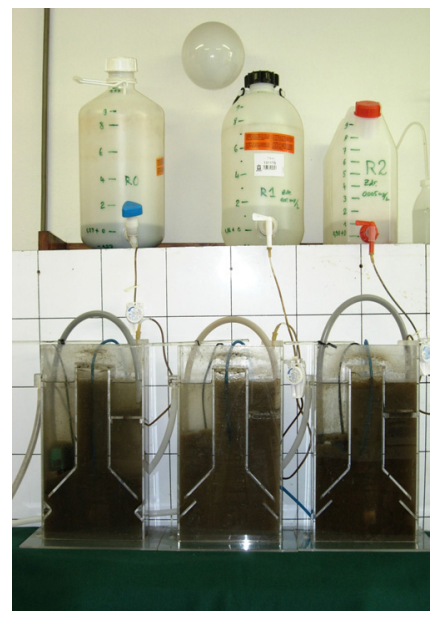

Figure 1: The experimental setup of the three pilot WWTP reactors $(\mathrm{RO}=$ control, $\mathrm{R} 1=0,05$ and $\mathrm{R} 2=0,005$ $\mathrm{mg} \mathrm{L}^{-1}$ of pharmaceutical mixture).

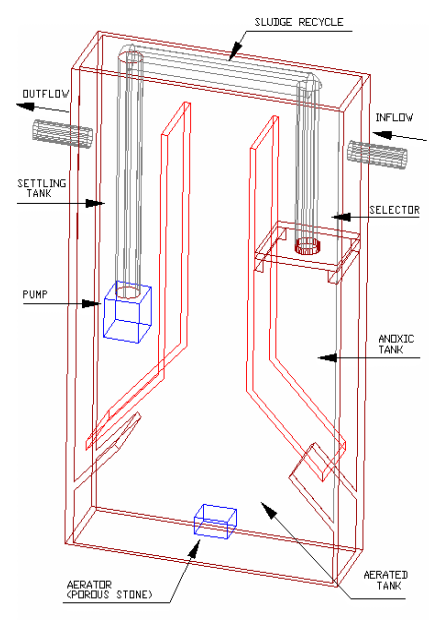

Figure 2: The 3D scheme of the pilot reactor showing inflow, selector, anoxic anaerobic tank, aerated tank, settler with sludge return to aerated tank and sludge recycle. 
All three reactors are fed with an aqueous nutrient and mineral solution, while NSAIDs are added in $\mathrm{R}_{1}\left(0,05 \mathrm{mg} \mathrm{L}^{-1}\right)$ and $\mathrm{R}_{2}\left(0,005 \mathrm{mg} \mathrm{L}^{-1}\right)$ only. The flow rate of the nutrient-mineral solution was set at approximately $2,0 \mathrm{~L}$ per day, with hydraulic residence time of 48 hours. We collect both influent and effluent samples. During first six months of operation, samples were collected on a weekly basis and then on monthly basis. Each sample is acidified, filtered and stored at $4^{\circ} \mathrm{C}$ prior to analysis.

\section{Results and discussion}

To estimate the extent of NSAID pollution in the Slovene environment, analytical procedure was developed, validated and described in details elsewhere (Kosjek et al. [2]). Using developed analytical procedure 16 river, 2 well and 11 tap water samples were collected. In all of the tap and well water samples NSAID residues were under the detection limit, while naproxen was determined in 9 and diclofenac in 6 out of 16 river water samples collected in 2004 (Table 1).

Table 1: Determined concentrations (ng/L) of the selected NSAIDs in river water samples.

\begin{tabular}{|c|c|c|c|c|}
\hline \multirow[b]{2}{*}{$\underline{\text { River samples }}$} & \multirow{2}{*}{$\begin{array}{l}\text { Date of } \\
\text { sampling }\end{array}$} & \multicolumn{3}{|c|}{ Concentration $\left(\mathrm{ng} \mathrm{L}^{-1}\right)$} \\
\hline & & Naproxen & Diclofenac & Ketoprofen \\
\hline \multirow{2}{*}{$\begin{array}{l}\text { KRKA before pharm. } \\
\text { factory }\end{array}$} & Jul-04 & $<$ LOQ & $<\mathrm{LOD}$ & $<\mathrm{LOD}$ \\
\hline & Sep-04 & $<\mathrm{LOD}$ & $<\mathrm{LOD}$ & $<\mathrm{LOQ}$ \\
\hline \multirow{2}{*}{$\begin{array}{l}\text { KRKA after pharm. } \\
\text { factory }\end{array}$} & Jul-04 & 313 & 282 & $<\mathrm{LOQ}$ \\
\hline & Sep-04 & 60 & 49 & $<$ LOQ \\
\hline \multirow[b]{2}{*}{ LJUBLJANICA1 } & Jul-04 & $<\mathrm{LOD}$ & $<\mathrm{LOD}$ & $<\mathrm{LOD}$ \\
\hline & Sep-04 & $<\mathrm{LOD}$ & $<\mathrm{LOD}$ & $<\mathrm{LOD}$ \\
\hline \multirow[b]{2}{*}{ LJUBLJANICA2 } & Jul-04 & 73 & $<\mathrm{LOQ}$ & $<\mathrm{LOD}$ \\
\hline & Sep-04 & $<\mathrm{LOD}$ & $<\mathrm{LOD}$ & $<$ LOQ \\
\hline \multirow[b]{2}{*}{ SAVA } & Jul-04 & 80 & 9 & $<\mathrm{LOQ}$ \\
\hline & Sep-04 & $<$ LOQ & $<$ LOQ & $<\mathrm{LOD}$ \\
\hline MURA & Jul-04 & 49 & 41 & $<\mathrm{LOQ}$ \\
\hline \multirow[b]{2}{*}{ DRAVA1 } & Jul-04 & 46 & 26 & $<\mathrm{LOQ}$ \\
\hline & Sep-04 & $<$ LOD & $<\mathrm{LOD}$ & $<$ LOD \\
\hline \multirow[b]{2}{*}{ DRAVA2 } & Jul-04 & 24 & 32 & $<\mathrm{LOQ}$ \\
\hline & Sep-04 & 42 & $<\mathrm{LOD}$ & $<\mathrm{LOD}$ \\
\hline PŠATA & Jul-04 & 17 & $<\mathrm{LOQ}$ & $<\mathrm{LOD}$ \\
\hline
\end{tabular}


The analytical procedure and its validation for isolation of UV filters and antimicrobial agents from aqueous samples is described in full elsewhere (Cuderman [6]. To estimate the pollution of the Slovene aquatic environment with UV filters and antimicrobial agents were analysed in 4 recreational and 4 waste waters. The results revealed the concentrations of the selected compounds to be above the limit of detection in half of the samples. Clorophene was not detected. The most frequently detected UV filter was Benzophenone-3 (11-400 ng/L), while of the antimicrobial agents we could only find traces of Triclosan in the river Kolpa (68 ng/L) and in one hospital effluent (122 ng/L). Table 2 gives the concentrations of compounds of interest in $\mathrm{ng} / \mathrm{L}$ range.

Table 2: $\quad$ Determined concentrations (ng/L) of the selected UV filters and antimicrobial agents in sea, pool, lake, river and wastewater.

\begin{tabular}{|c|c|c|c|c|c|c|c|c|c|}
\hline Matrix & $\begin{array}{l}\text { sampling } \\
\text { site }\end{array}$ & $\begin{array}{l}\text { Eusolex } \\
\text { HMS }\end{array}$ & $\begin{array}{l}\text { Eusolex } \\
6300\end{array}$ & \begin{tabular}{|l|} 
Eusolex \\
4360
\end{tabular} & \begin{tabular}{|l|} 
Eusolex \\
6007
\end{tabular} & $\begin{array}{l}\text { Eusolex } \\
2292\end{array}$ & $\begin{array}{l}\text { Eusolex } \\
\text { OCR }\end{array}$ & \begin{tabular}{|l|l}
$\mathbf{T r i}-$ \\
closan
\end{tabular} & $\begin{array}{l}\text { Cloro- } \\
\text { phene }\end{array}$ \\
\hline \multirow[t]{2}{*}{ River } & $\begin{array}{l}\text { Nadiža- } \\
\text { Soča }\end{array}$ & 345 & k LOD & $<$ LOD & $<\mathrm{LOD}$ & k LOD & 35 & $<\mathrm{LOD}$ & $<\mathrm{LOD}$ \\
\hline & Kolpa & 165 & < LOD & 114 & 47 & 88 & 34 & 68 & $<$ LOD \\
\hline \multirow{5}{*}{ Lake } & Rakitna & $<\mathrm{LOD}$ & kLOD & 85 & 34 & 92 & $<$ LOD & $<$ LOD & $<$ LOD \\
\hline & \begin{tabular}{|l} 
Lake \\
Bohinj
\end{tabular} & $<\mathrm{LOD}$ & $<\mathrm{LOD}$ & 32 & $<\mathrm{LOD}$ & < LOD & $<\mathrm{LOD}$ & $<$ LOD & $<\mathrm{LOD}$ \\
\hline & Šobec & $<$ LOD & $<\mathrm{LOD}$ & 58 & $<\mathrm{LOD}$ & < LOD & $<$ LOD & $<$ LOD & $<$ LOD \\
\hline & \begin{tabular}{|l} 
Lake \\
Bled \\
\end{tabular} & $<\mathrm{LOD}$ & < LOD & 66 & $<\mathrm{LOD}$ & < LOD & 31 & $<\mathrm{LOD}$ & $<\mathrm{LOD}$ \\
\hline & Bakovci & < LOD & < LOD & $<$ LOD & 24 & < LOD & < LOD & $<$ LOD & $<$ LOD \\
\hline \multirow{2}{*}{$\begin{array}{l}\text { swim- } \\
\text { ming } \\
\text { pool }\end{array}$} & $\begin{array}{l}\text { Kodeljev } \\
\text { o }\end{array}$ & $<$ LOD. & $<$ LOD & 103 & $<\mathrm{LOD}$ & < LOD & 15 & $<$ LOD & $<\mathrm{LOD}$ \\
\hline & Portorož & $<$ LOD & 330 & 400 & 17 & < LOD & $<$ LOD & $<$ LOD & $<\mathrm{LOD}$ \\
\hline $\begin{array}{l}\text { hospital } \\
\text { effluent }\end{array}$ & hospital 1 & $1<$ LOD & $<$ LOD & $<$ LOD & $<\mathrm{LOD}$ & < LOD & $<$ LOD & 122 & $<\mathrm{LOD}$ \\
\hline
\end{tabular}

\subsection{Removal of pharmaceutical substances in a PWWTP.}

To calculate the elimination efficiency for each of the NSAIDs understudy we compared the difference between the influent and effluent concentrations. The results (Table 3) show high and constant elimination of Ibuprofen, Ketoprofen and Naproxen $(>89 \%)$, whereas the elimination of Diclofenac was less efficient deviating significantly from the average removal rate (48 to $62 \%$ ). Our results are in agreement with the data from the literature (Zwiener and Frimmel [7]) and show Diclofenac to be more persistent to elimination in WWTP biodegradation.

In our future studies, we intend to optimise the reactor operating conditions in terms of higher and constant elimination of NSAIDs and study pharmaceutical elimination mechanism. The elimination of selected NSAID in PWWTP might be a consequence of physical, chemical or biochemical transformation paths, e.g. abiotic degradation, biological or photodegradation or adsorption to the 
active sludge or reactor wall surface. Our future research will focus upon understanding NSAID removal mechanisms in a PWWTP and isolation of stable degradation products. In our preliminary investigations we compared the total ion chromatograms (TIC) of the influent and observed additional chromatographic peaks possibly originating from NSAIDs degradation. Figure 3 shows chemical structures of the parent compound (diclofenac) and a compound which is, according to the TIC, mass spectra and its NIST library comparison a diclofenac's degradation product. However, the proposed structure will need to be confirmed using standard addition and high-resolution mass spectrometry.

Table 3: Elimination efficiency of the selected pharmaceuticals in PWWTP.

\begin{tabular}{|l|l|l|l|l|}
\hline \% REMOVAL RATE & median & average & standard deviation \\
\hline \multirow{2}{*}{ IBUPROFEN } & R1 & 98,9 & 94,6 & 9,2 \\
\cline { 2 - 5 } & R2 & 90,2 & 89,3 & 5,5 \\
\hline \multirow{2}{*}{ NAPROXEN } & R1 & 98,7 & 96,3 & 5,3 \\
\cline { 2 - 5 } & R2 & 89,7 & 90,7 & 4,8 \\
\hline \multirow{2}{*}{ KETOPROFEN } & R1 & 98,2 & 93,5 & 9,8 \\
\cline { 2 - 5 } & R2 & 90,5 & 90,8 & 6,2 \\
\hline \multirow{2}{*}{ DICLOFENAC } & R1 & 60,4 & 62,6 & 27,7 \\
\cline { 2 - 5 } & R2 & 59,5 & 48,1 & 27,5 \\
\hline
\end{tabular}<smiles>O=C(O)Cc1ccccc1Nc1c(Cl)cccc1Cl</smiles>

Diclofenac: 2-[(2,6dichlorophenyl)amino] benzeneacetic acid<smiles>C[Si](C)(C)OCc1ccccc1Nc1c(Cl)cccc1Cl</smiles>

Degradation product (silylised): trimethylsilyl ether of 2-[(2,6dichlorophenyl)amino]benzyl alcohol

Figure 3: Chemical structure of Diclofenac and its proposed degradation product.

\section{Conclusions}

In our study analytical procedures for determination of selected PPCPs were developed and include solid phase extraction with Strata ${ }^{\mathrm{TM}} \mathrm{X}$, derivatisation to trimethylsilyl esters and determination with GC-MSD. To estimate the PPCP pollution of Slovene aqueous environment, surface (river, tap, well and 
recreational waters) and wastewaters were sampled. In the case of NSAIDs (diclofenac, ibuprofen, naproxen and ketoprofen), the content of NSAIDs in all tap and well waters were under the detection limit, while naproxen was determined in most of river water samples and ketoprofen in every fourth (as a percentage) tested river samples. Our results also revealed concentrations of UV filters and antimicrobial agents to be under the limit of detection in most samples tested.

We also studied removal of selected NSAIDs in PWWTP and showed that with an exception of Diclofenac (up to 60\%) the other tested compounds were eliminated with over $90 \%$ efficiency. In the future, we will improve the elimination efficiency of NSAIDs and attempt to understand the mechanism of their elimination and identify their stable degradation products. Also, the spectra of PPCPs studied in PPWTP will be expanded to psychiatric drugs, lipidlowering agents etc.

To evaluate toxicity of complex environmental samples, we took samples from this study and subjected them to cytotoxic and genotoxic testings (bacterial SOS/umu test and mammalian MTT and comet assay). Results of this combined study will be presented at the same conference (Environmental Toxicology 2006).

\section{References}

[1] Ternes T.A. et al.: Environmental Science \& Technology 2004, October 15

[2] Kosjek T., Heath E., Krbavčič A., Environment International, 31(5), 679-685, 2005.

[3] Kümmerer K., Pharmaceuticals in the Environment; Sources, Fate, Effects and Risks; $1^{\text {st }}$ ed., Springer - Verlag Berlin Heidelberg New York, 1-7, 2001.

[4] Giokas D. L. et al.: Determination of residues of UV filters in natural waters by solid-phase extraction coupled to liquid chromatography-photodiode array detection and gas chromatography-mass spectrometry, J. Chromatogr. A, 1026, 289-293, 2004.

[5] Lindström A. et al.: Occurrence and Environmental Behavior of the Bactericide Triclosan and Its Methyl Derivative in Surface Waters and in Wastewater, Environ. Sci. Technol., 36, 2322-2329, 2002.

[6] Cuderman P., Heath E., Zupančič-Kralj L.: UV Filters and Antimicrobial Agents: Occurence and Remediation in Slovene Environment, snet for publication in Enviroment International (June 2006).

[7] Zwiener C., Frimmel F.H., The Science of the Total Environment 309, 201211. 